\title{
CARACTERIZAÇÃO HISTÓRICA E A LEGISLAÇÃO SOBRE O FUTEBOL NO BRASIL
}

Recebido em: 07/01/2017

Aceito em: 17/09/2017

Wagner Matias

Fernando Mascarenhas

Universidade de Brasília (UnB)

Brasília - DF - Brasil

RESUMO: O estudo apresenta as transformações no desenvolvimento do futebol no Brasil, a distribuição temporal e os temas privilegiados na legislação sobre essa modalidade. Para tanto foi realizada uma pesquisa documental no Portal da Legislação do Governo Federal por meio do descritor "futebol" e uma revisão de literatura. A periodização sobre as mudanças processadas na organização do futebol no país foram realizadas em quatro fases, conforme os modelos econômicos existentes no país. No que se refere ao ordenamento legal, observou-se a existência de um grande volume de normas após o início da vigência da Lei Pelé, com um domínio dos temas relacionados às finanças e a Copa do Mundo de 2014.

PALAVRAS CHAVE: Futebol. Legislação. Estado.

\section{HISTORICAL CHARACTERIZATION AND THE LEGISLATION ON FOOTBALL IN BRAZIL}

ABSTRACT: The study presents the transformations in the development of soccer in Brazil, the temporal distribution and the privileged themes in the legislation on this modality. For that, a documentary research was carried out in the Federal Government Portal of Legislation through the descriptor "football" and a literature review. The periodization on the changes processed in the organization of soccer in the country were carried out in four phases, according to the economic models in the country. With regard to legal regulations, a large volume of standards was observed after the beginning of the Pelé Law, with a domain of finance issues and the 2014 World Cup.

KEYWORDS: Soccer. Legislation. State. 


\section{Introdução}

Para os brasileiros "il calcio è la cosa più importante delle cose non importanti"

1, a frase é do ex- treinador da seleção italiana da Copa do Mundo de 1994 Arrigo Sacci, mas bem que poderia ser de qualquer brasileiro, afinal: "quem não sonhou em ser um jogador de futebol"?². Obviamente que há exageros no que foi dito anteriormente, todavia, não resta dúvida que "a bola não é a inimiga como o touro, numa corrida" ${ }^{3}$, ao contrário, "o futebol é uma maneira de expressão da sociedade brasileira e um meio do cidadão nacional experimentar suas emoções mais profundas, tais como paixão, ódio, felicidade, tristeza, prazer, dor, fidelidade, resignação e coragem" (LAGES; SILVA, 2012, p. 2).

Nesse sentido, o Diagnóstico Nacional do Esporte (DIESPORTE) revelou que $51,6 \%$ da população do país que realiza alguma atividade física ou esporte joga futebol (BRASIL, 2015). A maioria dos brasileiros (81,6\%) são torcedores de algum clube ${ }^{4}$, sendo que em 2011, 93\% dos homens e 73\% das mulheres, dos 121 milhões que acompanhavam algum jogo ou programa esportivo por meio das emissoras de televisão possuía preferência por essa prática social ${ }^{5}$. No âmbito econômico, a indústria do esporte no Brasil representava no país em 2012 o total de 1,6\% do Produto Interno

\footnotetext{
1 "O futebol é a coisa mais importante dentre as menos importantes". Disponível em: http://blogs.ne10.uol.com.br/torcedor/2012/04/01/arrigo-sacchi-completa-66-anos/. Acesso em: $12 / 05 / 2016$

${ }^{2}$ A frase é um excerto da música "é uma partida de futebol” da banda Skank, de composição de Samuel Rosa e Nando Reis.

${ }^{3}$ Extrato do Poema "O futebol brasileiro evocado da Europa" de João Cabral de Melo Neto. Disponível em: http://cartamaior.com.br/?/Editoria/Cultura/Joao-Cabral-de-Melo-Neto-e-o-Futebol/39/27734. Acesso em: 10/05/2016.

4 Informação disponível em: http://esportes.terra.com.br/futebol/maioria-dos-brasileiros-nao-torce-paranenhum-time-diz-pesquisa,e8d9854e2ecc83df8c059242372a5ccfwf6wpvew.html. Acesso em: $17 / 06 / 2016$

5 Informações disponíveis em: http://olance.com.br/maioria-dos-brasileiros-assitem-jogos-de-futebol/. Acesso em: 13/05/2016.
} 
Bruto (PIB), pouco mais que Alemanha $(1,5 \%)$ e menos que EUA $(2,1 \%)$ e Inglaterra $(1,8)$. O futebol configura metade desse $1,6 \%$ do $\mathrm{PIB}^{6}$.

Diante de sua importância social e econômica para o país, o futebol é constantemente objeto de discussão no Congresso Nacional e de normatização, inclusive hegemoniza o conteúdo legislativo do setor, se sobrepondo às especificidades e demandas de outras modalidades esportivas menos populares (ATHAYDE et al., 2016).

Os gestores e legisladores desde as primeiras décadas do século XX estabelecem ordenamentos legais que regulam o funcionamento e a relação das entidades ligadas ao futebol com o Estado. Porém, questiona-se: quais são os temas privilegiados pela legislação sobre o futebol no Brasil? No levantamento realizado por Silva et al. (2009) não foi encontrado nenhum estudo que tivesse feito tal mapeamento. Desse modo, esta pesquisa busca apresentar a trajetória do marco legal sobre o futebol no Brasil nas suas diferentes fases, bem como apontar os temas predominantes. Para tanto, é importante também apresentar as características do desenvolvimento dessa modalidade no país conforme a dinâmica política e econômica da sociedade brasileira.

\section{Procedimento Operacionais}

Este estudo caracteriza-se como uma pesquisa exploratória, de cunho qualitativa, que se apoia no levantamento documental e na revisão de literatura. Os documentos coletados foram organizados, filtrados e categorizados tendo como parâmetro as construções de Franco (2008).

A pesquisa documental compreendeu o levantamento da legislação sobre o futebol produzida em âmbito federal. A procura e localização do ordenamento legal

\footnotetext{
${ }^{6}$ Informações disponíveis em: https://www.pluriconsultoria.com.br. Acesso em: 18 maio 2016.
} 
realizaram-se por meio de busca no Portal da Legislação do Governo Federal ${ }^{7}$, filtrando os documentos por: (i) tipo de ato; (ii) situação; (iii) ano; (iv) data; (v) número; (vi) origem etc. A busca inicial no site adotou o formato simples a partir do descritor "futebol" - e retornou o total de 90 documentos.

Para ordenar e classificar os dados, utilizamos cinco etapas de filtragem - sendo algumas delas pertencentes à análise de conteúdo proposta por Franco (2008), a saber: (i) tipo de ato, adotamos apenas Decreto-Lei (DEL), Decreto do Poder Legislativo (DPL), Decretos, Leis; (ii) ano de publicação, mantivemos os documentos jurídicos publicados até 30/06/2016; (iii) leitura flutuante ${ }^{8}$, tomando como referência as ementas das leis, para excluir aquelas que não diziam respeito direta ou indiretamente ao futebol.

A revisão de literatura foi realizada a partir das categorias formação social brasileira, Estado, futebol e "Modernização Conservadora" do futebol. A seguir é apresentada a periodização do desenvolvimento do futebol no Brasil e na sequência a distribuição temporal e as temáticas privilegiadas na legislação.

\section{O Futebol no Brasil: Do Falso Amadorismo ao Futebol- Mercadoria}

Apesar da existência dos jogos com bola desde os tempos mais remotos da humanidade, o futebol é um sistema regulamentado de competição física que surge no processo de urbanização e industrialização da Europa no século XIX. "O futebol provém de um acordo de cavalheiros que doze clubes ingleses selaram no outono de 1863, numa taverna de Londres. Os clubes assumiram as regras estabelecidas em 1846 pela Universidade de Cambridge" (GALEANO, 2015, p. 33).

\footnotetext{
${ }^{7}$ Disponível em: $<$ https://www4.planalto.gov.br/legislacao>. Acesso em: 05 nov. 2015.

${ }^{8}$ Segundo Franco (2008, p. 52), a leitura flutuante é uma das etapas de pré-análise e tem como objetivo estabelecer um contato inicial "com os documentos a serem analisados e conhecer os textos e as mensagens neles contidas".
} 
O processo de expansão do futebol pelo planeta ocorreu conjuntamente com a ampliação da dominação do império inglês por meio do comércio. O modo de vida dos ingleses, seus aspectos culturais, dentre eles o futebol, acompanhavam as expedições mercantis. Sobre isso Hobsbawn (1995, p.97) diz:

O esporte que o mundo tornou seu foi o futebol de clubes, filho da presença global britânica [...]. Esse jogo simples e elegante, não perturbado por regras e/ou equipamentos complexos, e que podia ser praticado em qualquer espaço aberto ou menos plano do tamanho exigido [...] tornou-se genuinamente universal.

Portanto, a introdução do futebol na América Latina, especialmente na Argentina e no Brasil está intrinsicamente relacionado às conexões com o império britânico. "A presença constante de suas embarcações, associada à implantação de ferrovias e diversos outros equipamentos em nosso território [...], viabilizou relativo contato com diversas práticas socioculturais inglesas, dentre elas o futebol" (MASCARENHAS, 2001, p. 47). Não é por acaso que a primeira federação nacional na América do Sul surge na Argentina, que possuía naquela época fortes laços comerciais com a Grã-Bretanha.

Esse fenômeno rapidamente vai ocupando os espaços de outras modalidades nos clubes sociais no Brasil, como o remo e o críquete, e passa a ser a fonte inspiradora para a criação de novos clubes, inclusive de operários ${ }^{9}$ (GUTERMAN, 2014).

Nesse momento, é importante identificar que o futebol inicialmente fechado aos clubes da elite do país e de imigrantes, ao longo das primeiras décadas do século XX vai ganhando as periferias e saindo do eixo Rio- São Paulo. Para Rodrigues (2007), essa seria a primeira fase do desenvolvimento do futebol no Brasil, que começa em 1894 e

\footnotetext{
${ }^{9}$ Não iremos discutir neste trabalho as questões relacionadas aos precursores dessa modalidade no Brasil, porém, a título de registro é importante apontar que há divergências na literatura se de fato Charles Miller é o "pai" desse fenômeno nas terras brasileiras. Sobre isso ver Freixo (2014).
} 
termina em 1905, com um caráter elitista, sem a presença de negros nas disputas entre clubes da época e com uma perspectiva de disciplinamento da juventude aristocrática.

Para esse autor teríamos cinco momentos distintos no desenvolvimento dessa modalidade no país. Além da citada anteriormente há uma segunda que começa em 1905 e vai até 1932, que se caracteriza pelo amadorismo aristocrático ou "falso amadorismo" dos clubes brasileiros e pela "proletarização" do futebol. A terceira fase inicia em 1933 com a profissionalização dos atletas, passando pelos os ordenamentos legais que dispõe sobre o papel tutelar do Estado e conclui com a realização da Copa do Mundo de 1950. A quarta fase (1950-1970) seria aquela das grandes conquistas internacionais do futebol brasileiro, seja dos clubes ou da seleção brasileira. E, a quinta fase, denominada por Rodrigues (2007) de "Modernização Conservadora", começa após a conquista da Copa do Mundo de 1970 e termina em 2006. Ela possui como características os avanços e recuos da abertura da organização do futebol para o mercado. Para Santos (2011), a partir de 2006 temos um "salto" de modernização conservadora do futebol no país com a realização dos megaeventos esportivos e a legislação que garantia recursos e refinanciamento das dívidas dos clubes (Lei de Incentivo ao Esporte- lei $n^{\circ} 11.438 / 2006-$ e Timemania- lei no $\left.11.345 / 2006\right)$.

O recorte histórico proposto por Rodrigues (2007) e Santos (2011) é uma possibilidade para realizar a periodização do desenvolvimento do futebol no Brasil, porém, preferimos trabalhar o desenvolvimento do futebol conforme as fases da formação econômica do país, ou seja: expansão cafeeira e primórdios da industrialização (1889-1929)- República Velha; Nacional- Desenvolvimentismo, substituições das importações e a industrialização (1930-1979); crise, instabilidade e 
transição (década de 1980); e Modelo Liberal- Periférico, a partir de $1995^{10}$ (GONÇALVES, 2014).

\section{Primeira Fase: Distinção Social e "Falso Amadorismo"}

O primeiro momento de organização do futebol brasileiro reflete o cenário nacional de segregação entre as classes sociais. Trata-se de ter o futebol como símbolo de distinção social, algo que colocava as nossas elites em patamar semelhante àquelas da Inglaterra. Contudo, esse também é o período de surgimento dos clubes de massa, como por exemplo, o Corinthians Paulista, fundado por um grupo de artesãos e pequenos comerciantes em 1910 (OURIQUES, 1999, p. 23).

Nessa quadra histórica que começa em 1894 e vai até 1929 está presente o "falso amadorismo", com o pagamento de "bichos" (já que não era permitido o vínculo do jogador com o clube) e a inserção de pobres e negros nos grandes clubes que estavam se formando na época, como o Vasco da Gama (RODRIGUES, 2007).

Esse é um período de intenso debate sobre os rumos desse esporte, mas principalmente do destino político do Brasil. Os questionamentos sobre a "pureza" do futebol e o domínio da República por oligarcas eram temas latentes na sociedade civil. Porém, se a massificação desse esporte não era bem vista pela aristocracia, por outro lado, ele atendia aos seus interesses ao canalizar as energias das classes baixas que estavam levantando contra o regime vigente. Assim, o futebol torna-se uma importante ferramenta de disciplina e civismo (GUTERMAN, 2014).

\footnotetext{
${ }^{10}$ A colonização de exploração e o período de independência e economia agroexportadora escravista (1822-1889) não serão tratados diretamente nesse texto, porém são determinantes para o modelo econômico e político do século XX.
} 


\section{Segunda Fase: Profissionalização, Tutela Estatal e da Projeção Internacional}

As mudanças políticas e econômicas ocorridas no país a partir de 1930, com a ascensão das frações da burguesia vinculadas a indústria e ao comércio e a manutenção da fração agrária no bloco de poder, bem como as conquistas de alguns direitos sociais e a restrição dos direitos políticos marcam o fim na República Velha e o início da era desenvolvimentista no país ${ }^{11}$. A mudança existente é principalmente na economia com a substituição, gradual, do modelo agroexportador para a economia industrial, porém, sem romper com os latifundiários e com os seus privilégios (GONÇALVES, 2014).

De forma combinada estas frações conviveram no interior do Estado. Oliveira (2011, p. 60) sintetiza da seguinte maneira:

A expansão do capitalismo no Brasil se dá introduzindo relações novas no arcaico e reproduzindo relações arcaicas no novo, um modo de compatibilizar a acumulação global, em que a introdução das relações novas no arcaico libera força de trabalho que suporta a acumulação industrial urbana e em que a reprodução de relações arcaicas no novo preserva o potencial de acumulação liberado exclusivamente para fins de expansão do próprio novo.

Entre uma modernização mais acelerada e os interesses dos senhores proprietários de terra, "prevaleceu uma acomodação intermediária, na qual se barganhava certa contenção da heteronomia nos níveis econômicos e técnicos, ao lado de uma contenção do mercado interno moderno, neutralizando as vantagens econômicas da criação de um Estado nacional” (BEHRING, 2008, p.76).

No bojo das mudanças políticas e econômicas da década de 1930 inicia-se a segunda fase do desenvolvimento do futebol no Brasil que irá até 1979. Nesse período com mais de cinquenta anos de atraso em relação à Inglaterra, os atletas de futebol

\footnotetext{
11 A era desenvolvimentista ou nacional-desenvolvimentismo inicia em 1930 e vai até 1979 e se caracteriza pela economia industrial, pelo crescimento do mercado interno, avanços (limitados) nas dimensões sociais, políticas institucionais, em contrapartida, houve vários momentos de redução dos direitos políticos e nenhuma reforma estrutural relacionadas a diminuição da concentração de riquezas e renda. Sem dúvida, uma das heranças desse período é a injustiça social (GONÇALVES, 2014).
} 
passam a receber como profissionais. Ressalta-se que da mesma forma que ocorreu com os ingleses, os nossos dirigentes eram amadores e os atletas profissionais. Desse modo, os dirigentes diziam que o ideário aristocrático do esporte estava preservado, ao passo que os espetáculos para a população urbana se consolidavam (OURIQUES, 1999).

No Brasil a lógica profissional se desenvolve a partir do momento em que a formação social brasileira rompe, ainda que parcial e de forma lenta, com as raízes agrárias. O cenário de modernização do país a partir de 1930, com a forte presença do Estado regulando os diferentes setores da vida humana configura o cenário de profissionalização dos atletas, mas a administração dos clubes continua sustentada sob o amadorismo.

Proni (1998) adverte que os níveis de mercantilização do futebol dessa época são bem inferiores ao que temos na atualidade. Apesar de ser consumido pelas massas daquele período foi somente com a reestruturação do modo de produção capitalista em meados da década de 1970, com a presença da televisão e do marketing que subsumiu completamente o futebol na sua forma mercadoria (futebol de espetáculo).

Nos anos 1930 um conjunto de fatores foi determinante para a profissionalização dos atletas de futebol, o que foi regulamentada apenas em 1976, quais sejam: a preocupação com o êxodo dos jogadores do Brasil para os clubes internacionais, já sob a ordem profissional; a legislação trabalhista e social do Governo Vargas; a pressão da imprensa pela profissionalização; a criação da Federação Brasileira de Futebol com uma liga profissional independente da Confederação Brasileira de Desporto (CBD); as disputas até 1937 entre as federações paulistas e cariocas. Diante desses aspectos, a CBD reconheceu o profissionalismo dos atletas e passou a ser a única representante do esporte no país (GUTERMAN, 2014). 
De acordo com Guterman (2014, p. 81) o futebol entrou para agenda do governo de Getúlio Vargas em 1938 com a Copa do Mundo.

\begin{abstract}
Naquela oportunidade, estava claro que o esporte em geral se transformara em veículo da afirmação da superioridade nacionalbasta lembrar a Copa de 1934, na Itália fascista, e a Olímpiada de 1936, na Berlim nazista. A importância que o evento possuía para a consolidação do Estado Novo se evidenciou na escolha da "madrinha" da seleção, a própria filha de Getúlio, Alzira. Por trás disso estava a disposição do governo financiar a seleção e de esperar dela uma resposta à altura das ambições do regime e da formação desse "novo homem" brasileiro.
\end{abstract}

A "paixão" dos brasileiros estava ganhando forma e o governo não poderia deixar de capitalizar esse sentimento a favor de seus projetos. A ação estatal foi materializada pelo Decreto 3.199/1941 que deu plenos poderes ao Conselho Nacional de Desportos (CND), órgão vinculado ao poder executivo federal para organizar o esporte, principalmente, o futebol no país.

O fim da primeira passagem de Getúlio Vargas pelo poder é marcado por avanços na legislação trabalhista e social, pelo crescimento da industrialização, mas por restrição de direitos políticos e perseguições a opositores, com forte concentração de poder e domínio sobre a sociedade civil.

O período de democracia formal que inicia em 1945 e termina em 1964 é composto por turbulências políticas e forte presença do Estado e do capital estrangeiro na economia. Ao Estado coube o papel de garantir as condições de produção, investindo na infraestrutura e nos demais setores que a iniciativa privada não possuía interesse e ao capital estrangeiro, coube o incremento tecnológico e a instalação de filiais no país (OLIVEIRA, 2003).

Durante a década de 1950 o país consolida a predominância do setor industrial em relação ao setor agrário no Produto Interno Bruto (PIB). Sobre isso é importante 
destacar o papel do governo de Juscelino Kubsticheck na atração de filiais de empresas estrangeiras e recursos para o desenvolvimento da infraestrutura e da modernização da indústria. Essa década chega ao fim com um país mais industrializado, com um sistema financeiro mais robusto, com a criação de bancos regionais e a criação do Banco Nacional de Desenvolvimento Econômico (BNDE), hoje Banco Nacional de Desenvolvimento Econômico e Social (BNDES), com a existência de fortes empresas estatais, como a Petrobras, e com um cenário atrativo para o capital estrangeiro.

Diante do interesse de posicionar melhor o país na geopolítica internacional e atrair mais recursos, o Brasil sediou a Copa do Mundo de 1950 e construiu o maior estádio de futebol do mundo, o Maracanã. As conquistas da seleção brasileira de futebol, dos clubes e mesmo de atletas de outras modalidades foram capitalizadas pelos governos, como se fosse um triunfo também deles. O futebol foi um dos bens culturais utilizados tanto na breve democracia quanto na ditadura civil-militar como forma cimento ideológico, tentando passar uma mensagem de unidade nacional e potência mundial em desenvolvimento ${ }^{12}$.

Após quatro anos de intensas disputas políticas e pressões sociais, a aliança entre empresários e militares produziram a partir de 1964 vinte e um anos de restrição dos direitos políticos, perseguições e mortes dos adversários do regime. Esse é mais um período obscuro da história do país que se tornou ainda mais "duro" a partir do Ato Institucional $n^{\circ}$ 5. "O AI-5 jogou o país na escuridão, sem data para acabar. Foi o chamado "golpe dentro do golpe", e aquilo que era para ser apenas "exceção", como

\footnotetext{
${ }^{12}$ Destaca-se que em muitos momentos o futebol foi usado politicamente por quem estava no poder para se autopromover, bem como para exaltar o regime vigente (caso do Fascismo e do Nazismo), mas também existem registros que os campos e as arquibancadas tornaram palcos de questionamento do status quo- os jogadores e os torcedores do Spartak de Moscou na União Soviética; a democracia corintiana no Brasil; as manifestações de torcedores nos estádios na Jordânia e Egito em 2009 e Síria 2011 contra os regimes políticos daqueles países; as manifestações mais recentes dos jogadores de futebol no Brasil, Bom Senso; as manifestações de 2013 e 2014 no Brasil durante a Copa das Confederações e a Copa do Mundo- (CHADE, 2015).
} 
tortura e prisões arbitrárias, passou a ser a norma do regime" (GUTERMAN, 2014, p. 158). O AI 5 ocorre no cenário de intensas mobilizações sociais contrarias ao regime, bem como no contexto de crescimento econômico do país, "milagre econômico", a partir da conjunção de arrocho salarial, para controle da inflação, e de um cenário internacional prospero, o que possibilitava a entrada de dinheiro estrangeiro no país, seja por meio de empréstimos ou com multinacionais.

Ao longo da década de 1970 o "bolo" cresce, mas não há distribuição de renda, o país continua com altos índices de desigualdade e com parcela significativa da população sem assistência do Estado. No âmbito do futebol, se dentro de campo o país estava bem representado, fora dele nenhuma mudança. A relação do Estado com as entidades de administração do esporte não sofreu alteração na forma de gestão dos clubes. A lógica que comandou a organização dos clubes e os torneios profissionais não foi uma puramente mercantil. O futebol esteve atrelado aos objetivos de disciplina e integração nacional da ditadura civil-militar.

Foer $(2005$, p. 111) diz que as proezas em campo eram vistas pelos militares como prova de que o Brasil poderia tornar-se uma potência internacional. "Nos anos 1970, os ditadores mostravam seu rosto em outdoors ao lado de seus slogans (“ Ninguém segura este país!"). Nos eventos oficiais, executava-se a música tema da conquista da Copa do Mundo de 1970 pela equipe liderada por Pelé”.

Nessa mesma década o modo de produção capitalista sofre com suas crises e o modelo fordista e o estado de bem estar social é combatido. Desde então o mundo vive sob um novo receituário, de acumulação flexível e de estado mínimo para o atendimento das necessidades sociais. O Brasil navega ao longo da década de 1970 ainda sob as bases do seu "milagre econômico", porém, um milagre para poucos que se tornou 
pesadelo no início dos anos 1980, com a queda do PIB em 5\% em 1983, com a diminuição de $7,3 \%$ da renda per capita no mesmo ano, o desemprego subiu $15 \%$, comparado a 1978, a inflação chegou a 211\% em 1983 e os salários perderam seu valor 5 vezes mais rápido do que 1978 (GUTERMAN, 2014).

A "crise" econômica e a pressão popular colocam fim a ditadura civil-militar e o país passa a seguir a cartilha do Fundo Monetário Internacional (FMI) e seu ideário neoliberal na organização produtiva e política. Sobre isso Gonçalves $(2014$, p. 57) diz:

Ao longo dos anos 1980 e, principalmente, no final desse período, os custos crescentes da instabilidade econômica, os interesses dos grupos dominantes, as pressões internacionais e os riscos de perda de legitimidade do Estado convergiam no sentido de direcionar o país para medidas liberalizantes. [...] O auge desse processo é o governo Collor (1990-1992), cuja ruptura com o modelo desenvolvimentista fundou os marcos do liberalismo econômico, que seria dominante no país nas décadas seguintes. Essa liberalização atingiu, ainda nesse governo, as esferas comercial e financeira das relações econômicas internacionais. Assim, iniciou-se o processo de significativa liberalização das importações e dos fluxos internacionais de capitais.

Nesse cenário fecha-se a segunda fase de organização do futebol no país. A lógica tutelar do Estado perde foça e os interesses do mercado surge como um ator importante para este setor.

\section{Terceira Fase: Da Tutela Estatal a Autonomia das Entidades Esportivas}

Entre 1980 e 1994 o Brasil, de acordo com Gonçalves (2014), passa por um momento de transição entre o modelo Nacional-Desenvolvimentista, baseado na economia industrial, com forte presença do Estado e do capital estrangeiro, com ganhos sociais, ainda que restrito a alguns grupos populacionais e com um doloroso período restrição dos direitos políticos, para um Liberal- Periférico, de domínio da fração 
financeira, com o rompimento de todas as amarras para o capital estrangeiro e com uma economia nacional baseada na exportação de commodities.

Com o fim da ditadura civil- militar em 1985, começa a florescer no país "uma nova república". Contudo, o período de redemocratização no Brasil não alterou a hegemonia das frações da burguesia no bloco no poder. Os membros de grandes empresas, de proprietários de terra, a burguesia de Estado e a média burguesia nacional continuaram dando as cartas no país (BOITO JR, 1996).

A nova Constituição Federal elaborada no governo Sarney, em 1988, registra algumas conquistas para os trabalhadores, mas surge no momento em que o mundo discute e implementa um modelo de regulação social e produção bem diferente daquele existente nos países centrais.

No âmbito esportivo a constituição de 1988 ao passo que estabelece o esporte como um direito, dá autonomia para as entidades esportivas, cedendo à pressão do mercado e das entidades esportivas por mais liberdade de atuação, tendo em vista que, a época, o CND ainda tinha plenos poderes para intervir na gestão destas organizações (OURIQUES, 1999).

O Estado, assim, deixa de ser o protagonista, abandonando o "intervencionismo" político característico das legislações anteriores. A administração pública continuava a financiar o esporte, mas a gestão e o estabelecimento de critérios de distribuição dos recursos ficavam a cargo das federações, confederações e do Comitê Olímpico Brasileiro. "O Estado sai de cena", as entidades esportivas passam a ter autonomia, sem abrir mão do fundo público (CASTELLANI FILHO, 2008).

No âmbito da organização do futebol essa terceira fase é marcado pela liberalização das parcerias dos clubes com o setor privado e, como dissemos, pela 
transição da tutela estatal para a autonomia das entidades esportivas. A Constituição de 1988 afasta a presença do Estado do campo esportivo, ao menos no que se refere a gestão dos clubes, federações e confederações. Isso começará a se consolidar com a lei Zico (Lei no 8.672/1993).

\section{Quarta Fase: O Mercado do Futebol no Brasil}

Destaca-se que a partir do final dos anos 1970 e início dos anos 1980, no cenário de fim do "milagre econômico", de intensificação das lutas e abertura política, de desigualdade social e de transformações na forma de organização do modo de produção capitalista, o campo esportivo e o futebol, particularmente, começam no mundo e no Brasil a reestruturar sua forma de produção. Esse momento marca a intensificação da acumulação de capital por meio do esporte. Esse novo setor se estrutura primeiro em alguns países da Europa (caso da Itália e Espanha) e se ramifica pelo globo, formando mercados periféricos.

No Brasil, o domínio da forma empresarial do futebol foi e ainda está sendo de forma lenta, gradual e com resistências dos grupos dirigentes. Ela se insere no contexto de implantação do novo modelo de desenvolvimento do país- o Liberal Periféricoadotado a partir de 1990 ainda no governo de Fernando Collor e, principalmente, a partir de 1995, com FHC. Ele pode ser visto pela:

[...] liberalização, privatização e desregulamentação; subordinação e vulnerabilidade externa estrutural; e dominância do capital financeiro. O modelo é liberal porque é estruturado a partir da liberalização das relações internacionais nas esferas comercial, produtiva, tecnológica e monetário-financeira; da implementação de reformas no âmbito do Estado (em especial na área da previdência social) e da privatização das empresas estatais, que implicam reconfiguração da intervenção estatal na economia e na sociedade; e de um processo de desregulamentação do mercado de trabalho, que reforça a exploração da força de trabalho. O modelo é periférico porque é uma forma 
especifica de realização da doutrina neoliberal e da sua política econômica em um país que ocupa posição subalterna no sistema econômico internacional, ao mesmo tempo em que se caracteriza por significativa vulnerabilidade externa estrutural nas suas relações econômicas internacionais. E, por fim, o modelo tem o capital financeiro e a lógica financeira como dominantes em sua dinâmica macroeconômica (FILGUEIRAS; GONÇALVES, 2007, p. 96).

O governo FHC (1995-2002) caracterizou-se pela política externa subordinada aos interesses dos EUA, por uma coalizão política com os partidos de centro e de direita, pelo domínio da fração financeira do Estado, pela liberalização e desregulamentação do mercado, pela exportação de produtos primários e importação de tecnologia, pela contrarreforma do Estado, estabeleceu o câmbio flutuante, aumentou os juros e o superávit primário e cortou ou reconfigurou gastos sociais. Como resultado: índices elevados de desemprego e desigualdade social; baixo crescimento econômico; déficits na balança comercial; e, desindustrialização (BEHRING, 2008).

A expectativa de rompimento com o Modelo Liberal-Periférico (MLP) com a chegada da coalizão liderada pelo Partido dos Trabalhadores (PT) em 2003 ao poder não ocorreu, ainda que tenha reduzido à desigualdade de renda e da pobreza e diversificado os parceiros comerciais, algo extremamente importante, o bloco de poder comandado pela fração financeira e politicamente pelo PT formou uma base governista no Congresso Nacional com partidos conservadores e velhas lideranças da política nacional, bem como manteve e consolidou o tripé do modelo de desenvolvimento do governo anterior (liberalização; domínio da fração financeira; vulnerabilidade estrutural, apoiada na exportação de commodities) (MATIAS, 2013).

No âmbito do futebol, as mudanças processadas na década de 1990, com a lei Zico (lei nº 8.672/1993) e lei Pelé (lei no 9.615/1998), como o fim da "lei do passe" e a possibilidade dos clubes tornarem empresas foram mantidas e aprofundadas nos últimos anos, com normas de consumo dos espetáculos (Estatuto de Defesa do Torcedor) e 
principalmente com fontes de financiamento para os clubes endividados. Alguns exemplos disso foram a Timemania (11.345/2006) e o Programa de Modernização e Responsabilidade Fiscal do Futebol (PROFUT), lei no 13.155. Além disso, houve uma atuação direta do Estado para garantir e impulsionar o mercado com a realização dos eventos e megaeventos esportivos, casos específicos da Copa das Confederações de 2013 e da Copa do Mundo de 2014.

Registra-se que as mudanças nos ordenamentos não foram realizadas sem resistência dos dirigentes das entidades esportivas e dos clubes. Eles atuaram diretamente no Congresso Nacional para ter os seus interesses atendidos (BELMAR, 2016). Assim, pode-se afirmar que os dispositivos legais pós-constitucionais são o resultado dos embates entre os interesses liberalizantes- que buscavam autonomia de mercado- e os interesses patrimonialistas, que entendiam essa liberalização como uma ameaça ao poder constituído oligarquicamente (MATIAS, 2013).

Por fim, cabe sinalizar que para cada fase deste panorama histórico sobre o desenvolvimento do futebol no Brasil prevaleceu um conjunto de ordenamentos, com características bem diferentes. No tópico seguinte será discutido isso, ou seja: a distribuição temporal e os temas predominantes na legislação brasileira sobre futebol.

\section{Distribuição Temporal e Temas Privilegiados na Legislação sobre Futebol}

Até 30/06/2016 foram identificados 90 ordenamentos produzidos sobre o futebol no Brasil, contudo foram excluídos do corpus de análise as designações (DSN) e as Medidas Provisórias (MPV). Assim, restaram 59 ordenamentos sendo: 04 Decretos- Lei (DEL); 06 Decretos do Poder Legislativo (DPL); 24 Decretos; 25 Leis (GRÁFICO 1). 
Gráfico 1: Tipos de legislação produzida sobre futebol no Brasil.

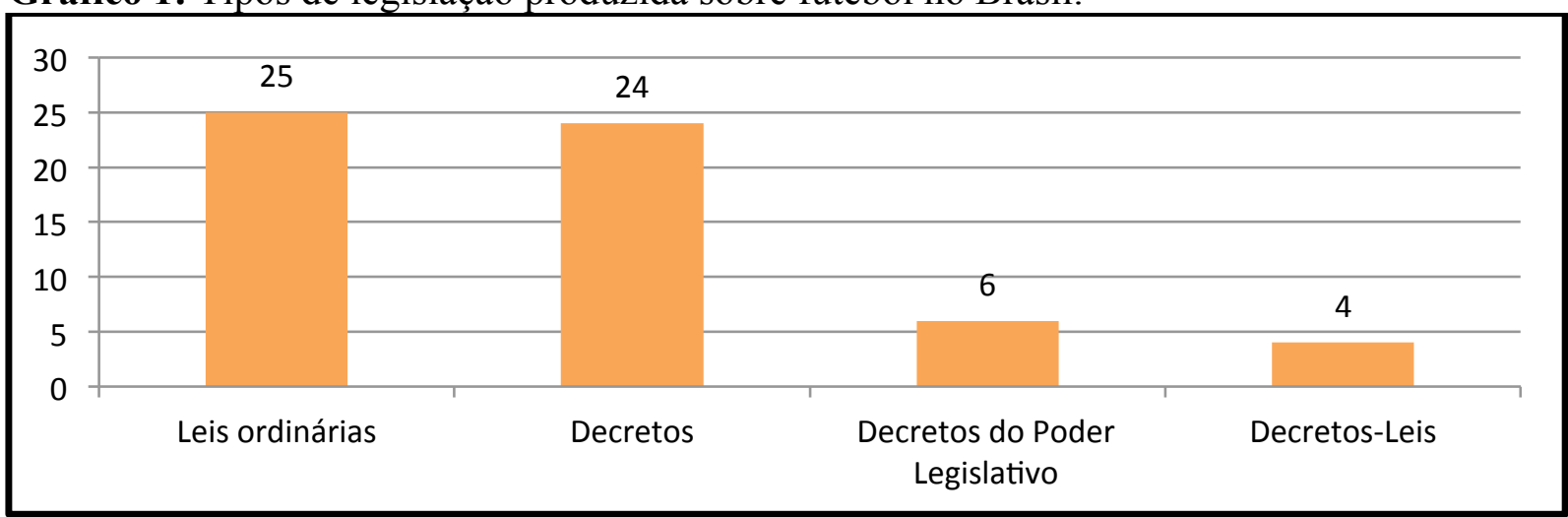

Fonte: https://www4.planalto.gov.br/legislacao.

Elaborado pelos autores (2016).

A maioria dos decretos regulamenta a implantação de leis aprovadas pelo Congresso Nacional e sancionada pelo presidente da república. Sobre os Decretos-Leis, é importante dizer que eles não são mais emitidos, pois, as normas que interferem na organização e no funcionamento da sociedade civil passam pela influência dos cidadãos e são aprovadas nos poderes legislativos.

O Gráfico 2 apresenta a distribuição anual da legislação do futebol no Brasil. Ele demonstra que quase a metade dos ordenamentos produzidos no país ocorreu depois da sanção da lei Pelé, no período de liberalização do futebol. Sendo assim, não resta dúvida que essa norma funcionou como um elemento fomentador para a legislação esportiva, estimulando a produção de normas jurídicas, seja para sua reformulação e atualização, seja para detalhar assuntos genericamente abordados por essa lei (ATHAYDE et al., 2016). 
Gráfico 2: Distribuição anual da produção legal sobre futebol no Brasil.

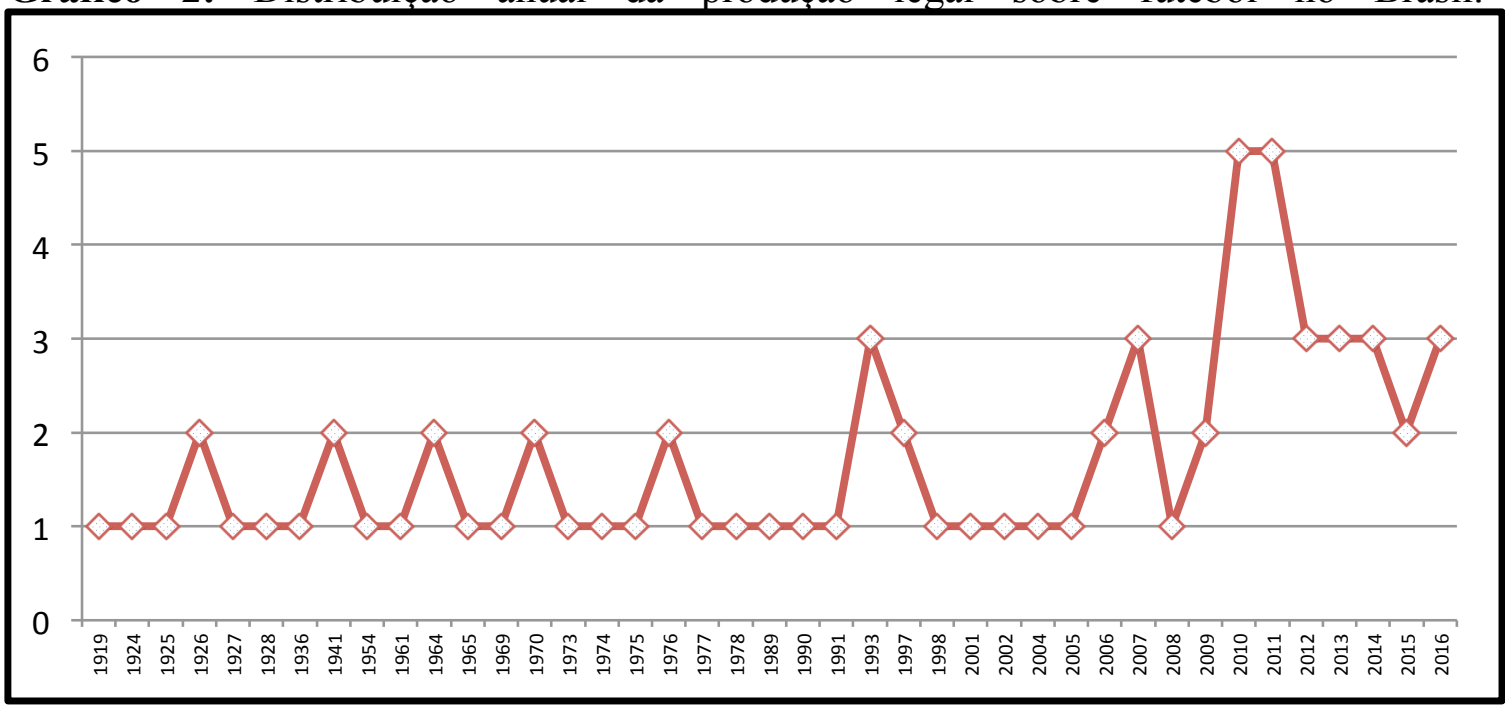

Fonte: https://www4.planalto.gov.br/legislacao.

Elaborado pelos autores (2016).

As primeiras normas para o futebol ocorrem na fase de formação dos grandes clubes e de estruturação dos campeonatos regionais (RODRIGUES, 2007). A relação do Estado com esse esporte não era orgânica, ela se baseava na concessão de benefícios aos clubes de futebol, caso da autorização ao Fluminense/RJ e ao Botafogo/RJ a contrair empréstimos e créditos especiais (Decreto do Poder Legislativo $n^{\text {o }}$ 3.955/1919; $n^{\circ} 5.824 / 1925 ; n^{\circ} 5.111 / 1926$ ), bem como da cessão de terreno ao Botafogo (Decreto do Poder Legislativo $\mathrm{n}^{\mathrm{o}}$. 5.011/1926).

A organicidade do Estado com o futebol inicia-se em 1941 com o Decreto Lei ${ }^{\circ}$ 3.199 que estabeleceu as normas gerais da organização do esporte no país. Ele foi adjetivado por outros três decretos: o de $n^{\circ} 9.267$ de 1942, que aprova o regimento do Conselho Nacional de Desporto (CND), o de $n^{\circ} 5.392$ de 1943, que dispôs sobre a administração das entidades esportivas e deu outras providências e o de $n^{\circ} 7.674$ de 1945, que estabelecia sobre a administração das entidades esportivas.

O Decreto Lei n ${ }^{\text {o }} 3.199 / 1941$ foi motivado pela "desorganização" da administração do futebol nacional. As disputas entre as federações paulista e carioca e a 
Confederação Brasileira de Desporto (CBD) eram conflituosas e dificultavam a participação da seleção nacional nos campeonatos internacionais. Sendo assim, o governo de Getúlio Vargas resolve disciplinar e fiscalizar a organização esportiva no país. O caráter corporativista da presença do Estado no futebol é marcado pela criação do CND, órgão com plenos poderes para autorizar a criação de federações e destituir seus presidentes. Assim, forma-se um cenário em que a relação entre o público e o privado não se separam, ao contrário, o primeiro exerce coerção sobre o segundo, impedindo-o de se desenvolver. Essa relação vai permanecer praticamente intocável por mais de 30 anos (MATIAS, 2013).

Esse Decreto foi substituído (de forma periférica) somente em 1975 pela lei $\mathrm{n}^{\mathrm{o}}$ 6.251. Vale destacar que nesse intervalo de tempo foi emitido o Decreto Lei $\mathrm{n}^{\text {o }} 594 / 1969$ que instituiu a loteria esportiva, um mecanismo que continua sendo utilizado até os dias atuais para reforçar o caixa dos clubes, como no caso da Timemania (Lei $\left.\mathrm{n}^{\mathrm{o}} 11.345 / 2006\right)$ e a Loteria exclusiva (Lotex), criada com o Programa de Modernização e Responsabilidade Fiscal do Futebol- PROFUT- (Lei nº 13.155/2015).

A reformulação na legislação do futebol ocorre de fato somente na década de 1990 com a lei Zico (Lei nº 8.672/1993) e a lei Pelé (Lei nº 9.615/1998). Elas vão regulamentar as relações mercantis nesse segmento e garantir a livre circulação dos jogadores de futebol.

Sendo assim, a produção legal a partir da década de 1990, especificamente após 1998, objetiva adequar o mercado do futebol brasileiro aos interesses do setor empresarial e ao mercado internacional dessa modalidade. Além disso, é importante mencionar que os picos nos anos de 2010 e 2011 na produção legal do setor 
demonstram a influência da realização da Copa das Confederações de futebol em 2013 e a Copa do Mundo 2014 na base jurídica do país.

Isto pode ser confirmado com o Gráfico 3 que apresenta os principais temas da legislação sobre futebol no Brasil. O conjunto dos ordenamentos jurídicos nos últimos anos regulamenta o funcionamento do mercado do futebol, sobretudo, busca garantir as condições de seu desenvolvimento.

Gráfico 3. Temas privilegiados da legislação sobre o futebol.

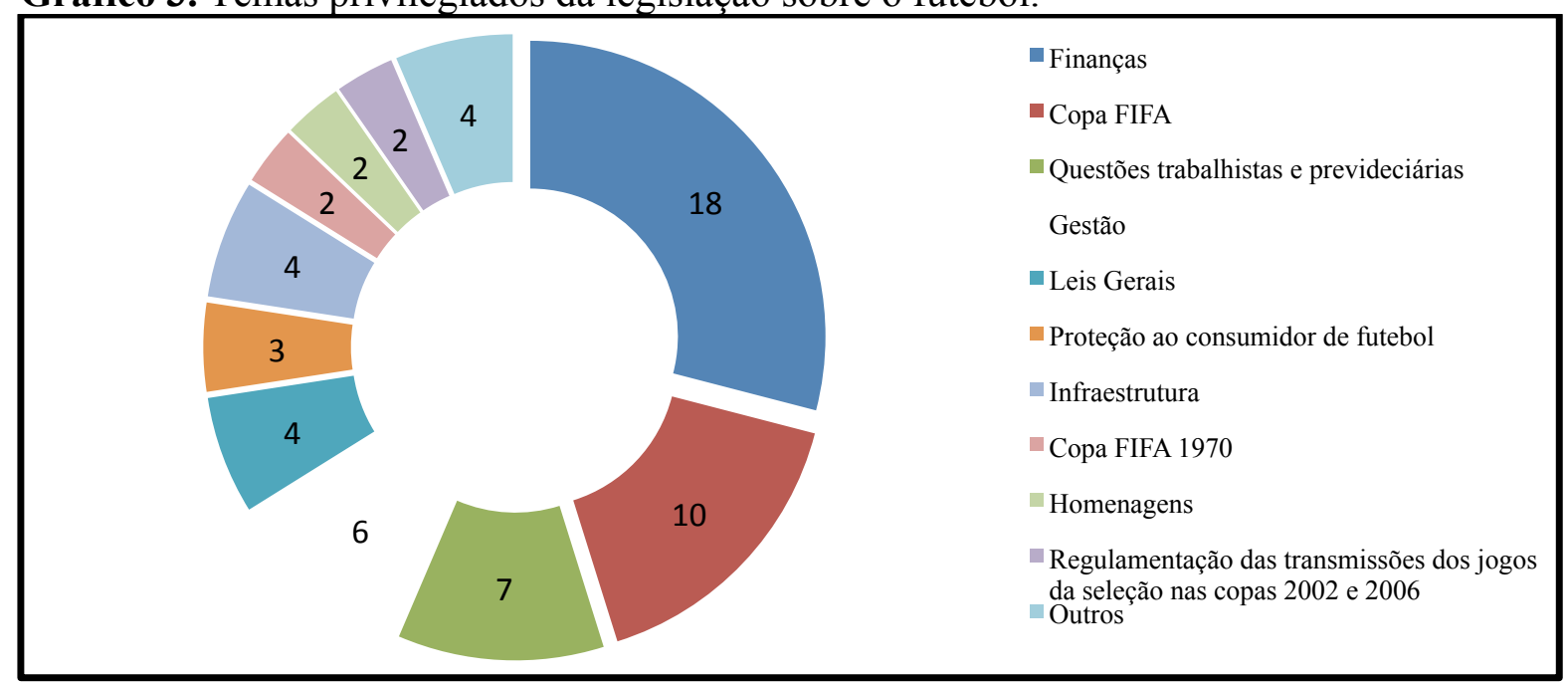

Fonte: https://www4.planalto.gov.br/legislacao. Elaborado pelos autores (2016).

De acordo com os dados apresentados no gráfico acima, a maior parte da legislação analisada trata do tema das finanças dos clubes, como o funcionamento da Timemania (exemplo: Decreto $\mathrm{n}^{\mathrm{o}}$ 6.912/2009) e da Lotex (exemplo: Decreto $\left.\mathrm{n}^{\mathrm{o}} 8.648 / 2016\right)$. Nos últimos anos o governo federal atuou no âmbito do futebol principalmente criando fontes de financiamento para os clubes endividados. $\mathrm{O}$ socorro do Estado ocorreu por meio de refinanciamento de dívidas- o primeiro ainda no governo Fernando Henrique Cardoso (FHC), o Programa de Recuperação Fiscal (REFIS)- Lei $\mathrm{n}^{\circ}$ 9.964/2000, já nos governos Lula e Dilma foram garantidos incentivos fiscais, 
alongamento das dívidas e criação de uma loteria, em 2007 foi a Timemania e em 2015 a Lotex.

A Timemania além de garantir recursos para os clubes também alongou as dívidas deles, com mais um refinanciamento. Porém, a previsão de arrecadação com essa loteria ficou quase cinco vezes menor do que o previsto e os clubes continuaram aumentando ano após ano as suas dívidas (MATIAS, 2013). Em 2015, o débito dos 20 maiores clubes do Brasil ficou superior a R\$ 6,3 bilhões $^{13}$. Diante desse cenário, os mesmos grupos de pressão (CBF, federações e clubes) que atuaram junto ao governo para criar a Timemania mais uma vez trabalharam com o executivo e o parlamento para obterem ajuda.

Nesse sentido, o governo federal sancionou em 2015 o Programa de Modernização e Responsabilidade Fiscal do Futebol (PROFUT), Lei n 13.155 . Com ela o Estado atua em duas frentes: 1) A medida busca garantir a sobrevivência dos clubes com diminuição, perdão, alongamento da dívida e a criação da Lotex. 2) Profissionalizar a gestão dos clubes e entidades de administração do futebol, com transparência, democracia nas eleições dos dirigentes e equilíbrio nas contas. A adesão dos principais clubes ao PROFUT (111 ao todo, 17 da série A) indica que eles deverão cortar gastos, profissionalizar a gestão e democratizar o seu sistema eleitoral. O mesmo vale para todas as instituições que recebem recursos públicos. Para acompanhar isso, o governo federal criou Autoridade Pública de Governança do Futebol- APFUT (Decreto $\left.\mathrm{n}^{\mathrm{o}} 8.642 / 2016\right)$.

\footnotetext{
13 Informação disponível em: http://blogs.lance.com.br/somoggi/os-numeros-escondidos-dos-balancosdos-clubes/. Acesso em: 03/06/2016.
} 
Destaca-se que com o PROFUT a expectativa governamental é equiparar a estrutura da produção do nosso futebol com aquilo que há de mais desenvolvido no mundo. No entanto, questiona- se se resolvido os problemas de gestão com o PROFUT passaríamos de fato a compor o primeiro mundo do futebol mundializado? Isso por si só vai atrair capital e deixar o mercado atrativo? É possível ser dominante em um setor da economia, caso do futebol e dependente nos outros? E, o melhor caminho é realmente esse, ou seja: seguir a tendência mundial de modernização via mercado?

O segundo tema mais abordado pela legislação foram às normas de exceção que fizeram adequações ao arcabouço jurídico brasileiro para atender às exigências estabelecidas pela FIFA para que o país sediasse a Copa das Confederações de 2013 e a Copa do Mundo de 2014. Um exemplo de concessão aplicada pelo Estado brasileiro em sua legislação diz respeito ao Estatuto do Torcedor (Lei 10.671 de 15 de maio de 2003), que no seu artigo 13-A, inciso II, prevê as condições para a permanência do torcedor dentro dos estádios. Entre as condições mínimas, estabelece: “não portar objetos, bebidas ou substâncias proibidas ou suscetíveis de gerar ou possibilitar a prática de atos de violência" (BRASIL, 2003). Contudo, a Lei Geral da Copa suprimiu temporariamente o artigo supracitado, tendo em vista atender aos acordos da FIFA com a InBev.

Outra medida questionável adotada pelo governo foi a adoção do Regime Diferenciado de Contratações (RDC) no setor público, aprovado em 2011 pelo Congresso Nacional. O RDC flexibiliza a Lei $n^{\circ} 8.666 / 93$, nos processos de licitações e licenciamento das obras para os megaeventos esportivos, o que pode acarretar ainda mais fragilidade na execução e fisscalização do uso dos recursos públicos. 
A esse conjunto de legislações ainda contam com leis estaduais próprias para os megaeventos, sejam leis de segurança, sejam leis de isenções, sejam leis de restrição territorial, enfim, normas que não estão de acordo com o ordenamento existente no país.

A terceira temática é a regulamentação das relações entre clube e jogador e os direitos previdenciários dos atletas, ao todo somam sete documentos. Essa temática reflete o processo de adequação da legislação nacional àquela praticada nos grandes centros do futebol e nos demais setores trabalhistas do Brasil.

$\mathrm{Na}$ sequência segue as normatizações sobre a gestão futebol, tanto governamental, por exemplo, a criação da Secretaria Nacional do Futebol e Defesa do Torcedor em 2012 (Decreto 7.784/2012), quanto sobre a gestão das entidades de administração e prática do futebol (por exemplo: Decreto nº 3.944/2001).

Por fim, destacamos a temática da infraestrutura e segurança, que se refere a cessão de terrenos públicos para os clubes (exemplo: Decreto 3.130/1941) e da proteção ao consumidor de futebol, que aborda principalmente questões relacionadas à segurança nos estádios (exemplo: Decreto 6.795/2009).

Registra-se que como o Decreto $\mathrm{n}^{\mathrm{o}} 3.199 / 1941$, a Lei $\mathrm{n}^{\mathrm{o}} 6.251 / 1975$, a Lei $n^{\text {o }} 8.672 / 1993$ e a Lei $n^{0} 9.615 / 1998$ dispõem sobre questões gerais sobre o esporte, ainda que as duas últimas tenham centralidade o futebol, preferimos não alinhá-las a uma categoria. O que chama atenção nelas é que o Decreto e a primeira Lei geral do esporte foram elaboradas em períodos ditatoriais, sob forte intervenção da sociedade política na sociedade civil, o que refletiu diretamente nos textos dessas leis. Já a Lei Zico e a Lei Pelé foram produzidas na década de 1990, com o Brasil já sob uma democracia representativa e sob o controle de um bloco de poder dominado pela fração 
financeira da burguesia, o que refletiu nessas legislações, com um discurso da necessidade da modernização/mercantilização das estruturas do futebol nacional.

Vale mencionar que as legislações apresentadas não tratam da garantia do acesso à prática do futebol como um direito, pelo contrário, o que se observou, principalmente, nos últimos anos foi uma preocupação com a criação das condições para um consumo mais qualificado e intenso dos espetáculos, das competições, das marcas e dos demais produtos em torno do futebol. A busca de melhoria nos padrões de produção do futebol brasileiro para que ele possa concorrer nos mesmos patamares daquilo produzido na Inglaterra, Espanha, Alemanha e Itália não é com a perspectiva da democratização, mas na possibilidade de geração de mais capital para quem investe. A lógica tendencial de mundialização da produção do futebol como uma mercadoria reflete diretamente na nossa legislação e na atração de grandes competições e espetáculos como foi a Copa do Mundo de 2014.

\section{Considerações Finais}

Em cada fase de desenvolvimento do futebol no Brasil prevaleceu um conjunto de normas com características diferentes. Na primeira (1984-1929) nota-se que existia uma relação institucional do Estado com entidades ligadas ao futebol. Assim, a legislação visava à concessão de bens e benefícios aos clubes e menos regulamentar o setor. Já na segunda fase (1930-1979) os ordenamentos surgem com a perspectiva de definir a relação do Estado com as entidades esportivas e o próprio funcionamento do campo esportivo, principalmente do futebol. A terceira fase (década de 1980 e início dos anos 1990) é o período de transição e marcado pela conquista do direito constitucional da autonomia das entidades de administração e prática esportiva. Por fim, 
a quarta fase (a partir dos anos 1990) é caracteriza pela regulamentação do segmento como um negócio, tendo a atuação estatal na garantia das condições de produção dos espetáculos pelos clubes e a realização de eventos e megaeventos esportivos, caso da Copa do Mundo de 2014.

Nesse sentido, parece ululante a "virada" no teor jurídico elaborado para o futebol no Brasil. No primeiro momento a centralidade era garantir a existência de uma burocracia, proporcionar as condições de sua existência e ter sob o controle do Estado o desenvolvimento do setor. A atuação corporativista do Estado estabelecia os papéis de cada entidade, regulava a existência delas e as subordinavam ao seu interesse. As mudanças no plano político, econômico e a tendência de subsunção real do futebol mundial muda o foco da legislação elaborada a partir da década de 1990. A presença do Estado ocorre numa perspectiva neocorporativista ainda tendo certo poder sobre as entidades, pois mantém algumas fontes de financiamento, mas elas possuem autonomia. Os ordenamentos seguem aqueles construídos nos países centrais, com ares “modernos", porém, por uma via "conservadora", mantendo privilégios e poderes dos "senhores da bola".

Por fim, registra- se que os ordenamentos sancionados nos últimos anos regulamentam a produção e o consumo do futebol, tendo o Estado um papel central na garantia das condições de produção. Nesse sentido, nos próximos anos é importante analisar como se insere o PROFUT, o ordenamento mais recente para essa modalidade, no cenário de modernização/mercantilização do futebol brasileiro. 


\section{REFERÊNCIAS}

ATHAYDE, P. F. et al. (no prelo). Panorama sobre o direito ao esporte no Brasil: a legislação esportiva. Revista Motrivivência.

BRASIL. Lei $\mathbf{n}^{\circ} \mathbf{1 0 . 8 7 1}$ de 15 de maio de 2003 . In https://www.planalto.gov.br/ccivil_03/Leis/L9615consol.htm. Acesso em: 13 nov. 2012.

. Diagnóstico Nacional do Esporte. Disponível em: $\overline{\mathrm{https}: / / w w w . e s p o r t e . g o v . b r / d i e s p o r t e / 7 . p h p . ~ A c e s s o ~ e m: ~} 10$ jun. 2016

BELMAR, Thiago Hinojosa. Grupos de interesse e o processo de modernização do futebol brasileiro: da redemocratização ao Bom Senso futebol clube. (Dissertação de Mestrado- Programa de Pós-Graduação em Ciência Política)- Faculdade de Filosofia, Letras- USP, São Paulo, 2016.

BEHRING, Elaine R. Brasil em Contra-Reforma: desestruturação do Estado e perda de direitos. 2. ed. São Paulo: Cortez, 2008.

BOITO JR, Armando. Hegemonia neoliberal e sindicalismo no Brasil. Revista Crítica Marxista, n. 3, São Paulo, Editora Brasiliense, 1996.

CASTELLANI FILHO, LINO. O Estado brasileiro e os direitos sociais: o esporte. In: Garcia, Carla Cristina; HÚNGARO, Edson Marcelo; DAMASCENO, Luciano Galvão (Org.). Estado, política e emancipação humana: lazer, educação, esporte e saúde como direitos sociais. Santo André: Alphrrabio, 2008.

CHADE, Jamil. Política, propina e futebol: como o "padrão FIFA" ameaça o esporte mais popular do planeta. Rio de Janeiro: Objetiva, 2015.

FILGUEIRAS, Luiz; GONÇALVES, Reinaldo. A economia política do governo Lula. São Paulo: contraponto, 2007.

FOER, Franklin. Como o futebol explica o mundo: um olhar inesperado sobre a globalização. Rio de Janeiro: Zahar, 2005.

FRANCO, M. L. P. B. Análise de Conteúdo. 3. ed. Brasília: Liber, 2008

GALEANO, Eduardo. O futebol ao sol e à sombra. Porto Alegre: L\&PM, 2015.

GONÇALVES, Reinaldo. Desenvolvimento às avessas: verdade, má-fé e ilusão no atual modelo brasileiro de desenvolvimento. Rio de Janeiro: LTC, 2014.

GUTERMAN, Marcos. O futebol explica o Brasil: uma história da maior expressão popular do país. São Paulo: Contexto, 2014.

HOBSBAWN. Era dos Extremos: O breve século XX (1914-1991). São Paulo: 1995. 
LAGES, Carlos Eduardo Dias Munaier; SILVA, Silvio Ricardo da. Futebol e lazer: diálogos e aproximações. Licere, v. 15, v.1, 2012.

MASCARENHAS, Gilmar. A bola nas redes e o enredo do lugar: uma geografia do futebol e de seu advento no Rio Grande do Sul. Tese de Doutorado. Universidade de São Paulo, Departamento de Geografia da Faculdade de Filosofia, Letras e Ciências Humanas. São Paulo 2001. 276 p.

MATIAS, Wagner Barbosa. O enigma olímpico: o controvertido percurso da agenda e políticas de esportivas no Governo Lula. (Dissertação de Mestrado - Programa de Pósgraduação em Educação Física). Faculdade de Educação Física - UnB. Brasília, 2013.

OLIVEIRA, Francisco de. Os Direitos do antivalor: a economia política da hegemonia imperfeita. São Paulo: Vozes, 2003.

OLIVEIRA, Francisco de. Crítica à razão dualista: o ornitorrinco. São Paulo: Boitempo, 2011.

OURIQUES, Nilson Domingos. A modernização conservadora do futebol nacional. Dissertação de Mestrado defendida na Universidade Federal de Santa Catariana. Programa de Pós-graduação em sociologia política. Florianópolis, 1999. $175 f$.

PRONI, Marcelo Weishaupt. Esporte-espetáculo e esporte-empresa. Campinas, 1998. 275f. Tese (Doutorado em Educação Física) Faculdade de Educação Física, UNICAMP, 1998.

RODRIGUES, Francisco Xavier Freire. O fim do passe e modernização conservadora no futebol brasileiro (2001-2006). 2007. 345f. Tese (Doutorado em Sociologia) Instituto de Filosofia e Ciências Humanas. Universidade Federal do Rio Grande do Sul. Porto Alegre, 2007.

SANTOS, Mariângela Ribeiro Dos. O futebol na agenda do governo Lula: Um salto de modernização (conservadora) rumo a Copa FIFA 2014. Brasília, 2011. 222f. Dissertação (Mestrado em Educação Física)- Faculdade de Educação Física, UnB, 2011.

SILVA, Silvio Ricardo da et al. Levantamento da produção sobre o futebol nas ciências humanas e sociais de 1980 a 2007. Belo Horizonte, UFMG, 2009.

\section{Endereço dos Autores:}

Wagner Matias

Universidade de Brasília

Faculdade de Educação Física

Campus Darcy Ribeiro

Brasília - DF - 70.910-900

Endereço Eletrônico: wagner.matias@outlook.com

Fernando Mascarenhas 
Universidade de Brasília

Faculdade de Educação Física

Campus Darcy Ribeiro

Brasília - DF - 70.910-900

Endereço Eletrônico: fernando.masca@uol.com.br 